\title{
ClpP is involved in the stress response and degradation of misfolded proteins in Salmonella enterica serovar Typhimurium
}

\author{
L. E. Thomsen, ${ }^{1}$ J. E. Olsen, ${ }^{1}$ J. W. Foster ${ }^{2}$ and H. Ingmer ${ }^{1}$
}

Author for correspondence: H. Ingmer. Tel: +453528 2773. Fax: +453528 2757. e-mail: ingmer@biobase.dk

1 Department of Veterinary Microbiology, Stigboejlen 4, The Royal Veterinary and Agricultural University, DK-1870 Frederiksberg C, Denmark

2 Department of Microbiology and Immunology, University of South Alabama College of Medicine, Mobile, AL, USA

\begin{abstract}
Components of the ATP-dependent Clp protease complex are found in a wide range of prokaryotic cells and they are often expressed as part of the cellular stress response. To investigate the physiological role of the proteolytic subunit, ClpP, in Salmonella enterica serovar Typhimurium (S. typhimurium) an in-frame deletion of the clpP gene was constructed. Growth experiments revealed that clpP is important for the ability of $S$. typhimurium to grow under various stressful conditions, such as low $\mathrm{pH}$, elevated temperature and high salt concentrations. Since the stationary-phase sigma factor, RpoS, is a target of the Clp proteolytic complex, the effect of the clpP deletion in the absence of RpoS was examined; it was observed that growth of the $S$. typhimurium clpP mutant is affected in both an RpoS-dependent and an RpoS-independent manner. Analysis of the degradation of abnormal puromycyl-containing polypeptides showed that ClpP participates in the proteolysis of such proteins in S. typhimurium. These findings prompted an investigation of the growth of an Escherichia coli clpP mutant under various stress conditions. The growth of this $E$. coli mutant was affected by heat, salt and low $\mathrm{pH}$, although not to the same extent as observed for the $S$. typhimurium clpP mutant. The results of this study indicate that the $S$. typhimurium clpP mutant is generally more sensitive to environmental stress than the $E$. coli clpP mutant and it is proposed that this is due to a reduced ability to degrade misfolded proteins generated under these conditions.
\end{abstract}

Keywords: Salmonella typhimurium, Clp protease, RpoS

\section{INTRODUCTION}

The continuous requirement for adaptation of bacteria to starvation and physical stress has forced the development of very complex regulatory networks that respond to changes in the environment. During stress, abnormal or misfolded proteins will accumulate in the cell due to denaturation and errors in biosynthesis. The cell responds to this accumulation by increasing the synthesis both of molecular chaperones, which assist the proper folding or refolding of proteins, and of proteases, which degrade the proteins that cannot be refolded (Goff \& Goldberg, 1985). Energy-dependent protein degradation is important in both prokaryotic and eukaryotic cells and it is carried out by multimeric protein complexes, such as the proteasome of eukaryotic and archaeal cells (Kessel et al., 1995) and the ATPdependent proteases of bacterial cells (De Mot et al.,
1999). In addition to eliminating abnormal proteins, proteolysis also controls the level of naturally shortlived regulatory proteins (Mhammedi-Alaoui et al., 1994; Schweder et al., 1996) and therefore is essential for cell homeostasis and optimal metabolic activity (Gottesman, 1996).

In Escherichia coli, several ATP-dependent proteases have been characterized (for reviews see Gottesman, 1996; Miller, 1996; Porankiewicz et al., 1999). Among these is the Clp protease, which together with Lon accounts for up to $80 \%$ of the protein degradation in the cell (Goldberg et al., 1994; Laskowska et al., 1996; Porankiewicz et al., 1999). The Clp protease complex consists of a proteolytic component, ClpP, to which substrate specificity is conferred through association with either of the ATPases, ClpA or ClpX. Beside their functions in proteolysis, both ClpA and ClpX possess 
chaperone-like activities (Wawrzynow et al., 1995; Wickner et al., 1994). The Clp protease complex mediates the turnover of specific short-lived regulatory proteins (Mhammedi-Alaoui et al., 1994; Schweder et al., 1996), among them the stationary-phase sigma factor, $\sigma^{\mathrm{S}}$ (RpoS). RpoS regulates the expression of more than 50 genes in the response to stress or the entry into stationary phase (Hengge-Aronis, 1996, 2000; Loewen \& Hengge-Aronis, 1994; Schweder et al., 1996). During exponential growth the level of RpoS is low, in part due to degradation by ClpXP (Lange \& Hengge-Aronis, 1994). When cells enter stationary phase or encounter various stress conditions, the concentration of RpoS increases as a result of greater resistance to degradation by ClpXP (Schweder et al., 1996; Webb et al., 1999; Zgurskaya et al., 1997).

Components of the Clp complex are highly conserved in prokaryotic cells (Maurizi et al., 1990a; Wawrzynow et al., 1996). In Gram-positive bacteria ClpP is required for survival under various kinds of stress (Frees \& Ingmer, 1999; Msadek et al., 1998) and it has been shown that ClpP participates in the degradation of misfolded proteins generated under these conditions (Frees \& Ingmer, 1999; Gaillot et al., 2000; Kruger et al., 2000). In Gram-negative bacteria the role of ClpP during stress is less clear, as indicated by the lack of obvious phenotypes of an E. coli clpP mutant (Maurizi et al., 1990b). In recent studies mutants were generated in the $c l p P$ gene of Salmonella enterica serovar Typhimurium (referred to as Salmonella typhimurium) (Hensel et al., 1995; Webb et al., 1999; Yamamoto et al., 2001). S. typhimurium is a facultative intracellular pathogen that upon contact with host cells can promote its own entry (Galan, 1996). In this organism $c l p P$ is required for virulence in a mouse assay (Hensel et al., 1995; Webb et al., 1999; Yamamoto et al., 2001) and for growth and survival within peritoneal macrophages (Yamamoto et al., 2001). ClpP has also been found to be involved in the regulation of flagellum biosynthesis in S. typhimurium, and the lack of ClpP leads to a hyper-flagellate cell (Tomoyasu et al., 2002).

Since S. typhimurium encounters various hostile conditions during the infection process (Foster \& Spector, 1995), we were prompted to investigate the importance of ClpP for growth in the presence of stress. We find that clpP mutant cells have a reduced ability to grow compared to wild-type cells when exposed to high temperature, low $\mathrm{pH}$ or a high salt concentration. Furthermore, we demonstrate that the clpP mutant degrades puromycyl-containing polypeptides to a lesser extent than the wild-type, indicating that S. typhimurium ClpP is important for the degradation of misfolded proteins generated when exposed to stress.

\section{METHODS}

Media and bacterial strains. The bacterial strains used in this study are shown in Table 1. Luria-Bertani (LB) broth and M63 medium (Miller, 1992) were prepared as liquid or solid (1.5\% agar) media. Unless otherwise stated the strains were grown in
LB. Antibiotics were used at the following concentrations for both S. typhimurium and E. coli: $50 \mu \mathrm{g}$ ampicillin $\mathrm{ml}^{-1}, 30 \mu \mathrm{g}$ chloramphenicol ml $\mathrm{m}^{-1}$ and $20 \mu \mathrm{g}$ tetracycline $\mathrm{ml}^{-1}$.

General methods. P22 transductions were performed with P22HT105/int 201 as described by Maloy et al. (1996). For plasmid constructions, E. coli DH $5 \alpha$ was used. S. typhimurium KP1274 was used for transfer of DNA from E. coli to $S$. typhimurium. Electroporation and plasmid transformations were performed as described by O'Callaghan \& Charbit (1990) and Sambrook et al. (1989). Plasmid purification was performed according to the manufacturer's instructions (Qiagen).

Construction of a S. typhimurium clpP deletion mutant. Using a replacement recombination technique, a recombinant strain of S. typhimurium C5 carrying an 80 amino acid in-frame deletion of $c l p P$ was constructed. By PCR amplification of chromosomal $S$. typhimurium DNA a 750 bp fragment carrying part of the upstream region of $c l p P$ was obtained using the primers ClpP-B1 (5'-AGTAGATCTCGTCTGCTTACGAAGATCC-3') and ClpP-Ec1 (5'-AGAGAATTCCTGTCCCATACAAATGGTGC-3'), while a 642 bp fragment carrying the downstream part of $c l p P$ was obtained using the primers ClpP-Ec2 (5'-CTCGAATTCCCTGAAGCGGTAGAATACG-3') and ClpX-H1 (5'-CCTAAGCTTACGCCATTGCTGGTATCG-3').

The two fragments were digested with EcoRI/BglII and EcoRI/HindIII, respectively, and cloned into the BamHIHindIII sites of the thermosensitive vector pTSA29 (Phillips, 1999), resulting in the plasmid pLT11, carrying a $1376 \mathrm{bp}$ insert.

S. typhimurium C5 was transformed with pLT11 by electroporation and integration was promoted by incubation at $42{ }^{\circ} \mathrm{C}$ in the presence of ampicillin. To excise the plasmid from the chromosome, the integrants were grown overnight at $30{ }^{\circ} \mathrm{C}$ and plated in the presence of ampicillin. The excised plasmid was cured by incubation of the strain in the absence of antibiotics at $42{ }^{\circ} \mathrm{C}$. Forty ampicillin-sensitive colonies were analysed by PCR to identify mutants with an internal deletion. One colony gave a single $1376 \mathrm{bp}$ fragment, corresponding to the $c l p P$ gene with a $240 \mathrm{bp}$ deletion; the wild-type strain C5 gave a single $1616 \mathrm{bp}$ fragment (data not shown). The correct construction of the resulting $c l p P$ mutant (LT1100) was verified by sequencing the $c l p P$ gene.

Growth experiments. Growth was followed by diluting cultures (grown overnight at $37^{\circ} \mathrm{C}$ in LB) 100 -fold into LB and incubating either at $37^{\circ} \mathrm{C}$, at $45^{\circ} \mathrm{C}$, at $37^{\circ} \mathrm{C}$ with $5 \% \mathrm{NaCl}$, or at $37^{\circ} \mathrm{C}$ with the $\mathrm{pH}$ reduced to $\mathrm{pH} 4 \cdot 5$. The optical density was measured at $450 \mathrm{~nm}\left(\mathrm{OD}_{450}\right)$.

In plating experiments overnight cultures were diluted 100fold in LB and allowed to grow to $\mathrm{OD}_{450} 0.4$ at $37^{\circ} \mathrm{C}$. Samples $(10 \mu \mathrm{l})$ of culture were spotted on plates with or without $5 \%$ $\mathrm{NaCl}$. Plates were incubated overnight at either $37^{\circ} \mathrm{C}$ or $45^{\circ} \mathrm{C}$.

Immunoblotting. Western blot analysis using monoclonal anti- $\sigma^{\mathrm{S}}$ antibodies (obtained from Neoclone) was performed essentially as described by Lee et al. (1995). Cells were grown to the mid-exponential growth phase $\left(\mathrm{OD}_{600} \quad 0 \cdot 4\right)$ or late stationary phase ( $15 \mathrm{~h}$ growth) in LB. Equal amounts $(5 \mu \mathrm{g})$ of protein were loaded for each sample.

Two-dimensional protein gel electrophoresis. Two-dimensional SDS-PAGE analysis was performed as described by Spector et al. (1986) with minor modifications. Strains were grown in M63 supplemented with $0.05 \%$ Casamino acids at 
Table 1. Bacterial strains used in this study

\begin{tabular}{|c|c|c|}
\hline Strain & Genotype & Source \\
\hline \multicolumn{3}{|c|}{ S. typhimurium } \\
\hline JF2690 & UK1 rpoS: :Ap & Lee et al. (1995) \\
\hline JF3717 & UK1 $x b a-6014:: \operatorname{Tn} 10 \mathrm{dCm}\left(48 \%\right.$ linked to $\left.c l p P^{+}\right)$ & J. W. Foster, unpublished data \\
\hline JF3487 & UK1 $c$ pP $1:: \operatorname{Tn} 10 \mathrm{dTc}$ & Webb et al. (1999) \\
\hline C5 & Virulent wild-type & Hormaeche (1979) \\
\hline LT1100 & $\mathrm{C} 5 \Delta c l p P$ & This work \\
\hline LT1102 & LT1100 with Tn10 linked to $c l p P^{+}($linkage $48 \%)$ & JF3717 $\times$ LT1100, this work \\
\hline LT1103 & LT1102 $c l p P 1:: \operatorname{Tn} 10 \mathrm{dTc}$ & JF3487 × LT1102 \\
\hline LT1104 & LT1100 rpos::Ap & JF2690 $\times$ LT1100, this work \\
\hline LT1108 & LT1102 rpos: :Ap & JF2690 $\times$ LT1102, this work \\
\hline LT1115 & $\mathrm{C} 5 \mathrm{clpP} 1:: \mathrm{Tn} 10 \mathrm{dTc}$ & $\mathrm{JF} 3487 \times \mathrm{C} 5$ \\
\hline KP1274 & $\begin{array}{l}\text { LT2 (metA22 metE55 val galE496 rpsL120 xyl-404 H1-b nml H2-e,n,x } \\
\text { hsdL6 hsdSA29 }\left(\mathrm{r}^{-} \mathrm{m}^{+}\right)\end{array}$ & Enomoto \& Stocker (1974) \\
\hline \multicolumn{3}{|c|}{ 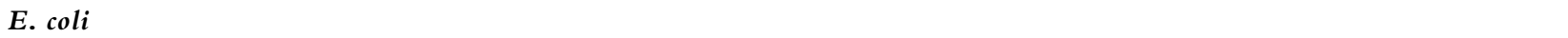 } \\
\hline DH5 $\alpha$ & $\begin{array}{l}\mathrm{F}^{-} \phi 80 \mathrm{~d} l a c Z \Delta \mathrm{M} 15 \Delta(\text { lacZYA-argF }) U 169 \text { deoR recA1 endA1 hsdR17 } \\
\left(\mathrm{r}_{\mathrm{k}}^{-} \mathrm{m}_{\mathrm{k}}^{+}\right) \text {supE44 thi-1 gyrA96 }\end{array}$ & Hanahan (1985) \\
\hline AMS6 & $\mathrm{K}-12\left(\lambda^{-} \mathrm{F}^{-} \Delta l a c\right)$ & Schultz et al. (1988) \\
\hline AMS6P & AMS6 but $c l p P ;$ Cam $^{\mathrm{r}}$ & Schweder et al. (1996) \\
\hline
\end{tabular}

$37^{\circ} \mathrm{C}$ until the $\mathrm{OD}_{600}$ was $0 \cdot 4$. The cultures were then transferred to $45^{\circ} \mathrm{C}$ and allowed to grow for $1 \mathrm{~h}$. Samples were labelled with ${ }^{35}$ S-translabel $\left(40 \mu \mathrm{Ci} \mathrm{ml}^{-1} ; 1.48 \times 10^{6}\right.$ $\mathrm{Bq} \mathrm{ml}^{-1}$; ICN Pharmaceuticals) for $3 \mathrm{~min}$. In the first dimension proteins were separated using ReadyStrip IPG Strips pH 4-7 (Bio-Rad) and in the second dimension an SDS$11.5 \%$ polyacrylamide gel was used.

Measurement of degradation of puromycyl-containing polypeptides. The experiment was performed essentially as described by Raina \& Georgopoulos (1990). S. typhimurium wild-type and $c l p P$ mutant cells were grown at $37^{\circ} \mathrm{C}$ in $\mathrm{M} 63$ until the $\mathrm{OD}_{450}$ reached $0 \cdot 4$. The cells were subsequently incubated with puromycin $\left(200 \mu \mathrm{g} \mathrm{ml}^{-1}\right.$, Sigma) for $10 \mathrm{~min}$ and then labelled with $30 \mu \mathrm{Ci}\left(1 \cdot 11 \times 10^{6} \mathrm{~Bq} \mathrm{ml}^{-1}\right)\left[{ }^{35} \mathrm{~S}\right]$ methionine per $\mathrm{ml}$ for $10 \mathrm{~min}$. The cells were washed and resuspended in M63 containing $500 \mu \mathrm{g}$ unlabelled methionine $\mathrm{ml}^{-1}$. Samples $(300 \mu \mathrm{l})$ were collected at $5 \mathrm{~min}$ intervals and precipitated with $6 \%$ trichloroacetic acid. The radioactivity of the acid-soluble fraction was measured by liquid-scintillation counting.

\section{RESULTS AND DISCUSSION}

\section{ClpP is important for growth under stress conditions in S. typhimurium}

With the aim of investigating the physiological role of ClpP in S. typhimurium C5, we constructed a clpP mutant (LT1100) by deleting an internal fragment corresponding to 80 amino acids, including the three amino acids known to be required for the proteolytic activity of ClpP in E. coli (Maurizi et al., 1990a; Wang et al., 1997). By Western-blot analysis using a ClpX antibody we confirmed that the deletion did not affect the expression of $c l p X$ located downstream of $c l p P$ (data not shown). When we investigated the growth of LT1100 at $37^{\circ} \mathrm{C}$ the growth rate was comparable to that of the wild-type in both enriched (Fig. 1) and minimal broth (data not shown). However, when mutant cells were shifted to $45^{\circ} \mathrm{C}$, the growth was impaired compared to the wild-type, as observed by a reduction in the growth rate and by the inability to reach the same density as the wild-type even after $24 \mathrm{~h}$ (Fig. 1). A high salt concentration $(5 \% \mathrm{NaCl})$ as well as low $\mathrm{pH}(\mathrm{pH} 4.5)$ also reduced the growth rate of the S. typhimurium clpP mutant (Fig. 1). Furthermore, when mutant and wildtype cells were plated either at $45^{\circ} \mathrm{C}$ or in the presence of $5 \%$ salt the ability of the mutant to form colonies was greatly reduced (data not shown). To verify that these differences were due to the lack of $c l p P$, we repaired the deletion by transducing the $c l p P^{+}$allele together with Tn10 from JF3717 into LT1100, resulting in LT1102 $\left(c l p P^{+}\right)$. Under all conditions tested LT1102 grew like wild-type cells (data not shown), confirming that it is the lack of functional ClpP that affects the growth during stress. Thus, our results reveal that the growth of the S. typhimurium clpP mutant is impaired when exposed to stress.

\section{ClpP affects growth of S. typhimurium independently of RpoS}

In both S. typhimurium and E. coli, the ClpXP protease is involved in the regulation of the level of RpoS by degradation and a clpP mutation results in increased concentrations of RpoS (Schweder et al., 1996; Webb et al., 1999). Since RpoS regulates or augments the expression of many stress-regulated genes in S. typhimurium and E. coli (Hengge-Aronis, 1996; Ibanez-Ruiz et al., 2000; Loewen \& Hengge-Aronis, 1994; O’Neal et al., 1994) we addressed whether the stress sensitivity observed for the clpP mutant was related to $r p o S$ by 

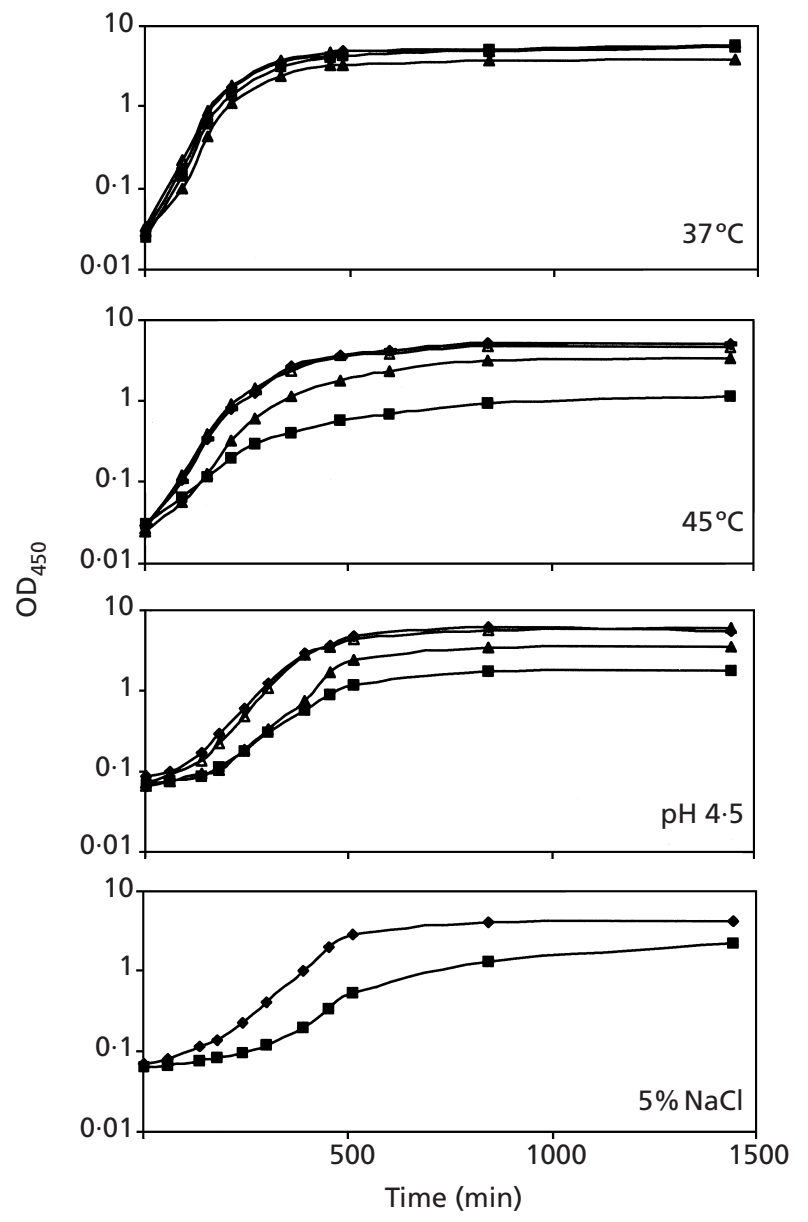

Fig. 1. The $S$. typhimurium clpP mutant LT1100 exhibits slower growth when exposed to stress. Overnight cultures were diluted into fresh medium and growth was followed under the following conditions: at $37{ }^{\circ} \mathrm{C}$; at $45^{\circ} \mathrm{C}$; at pH 4.5 at $37^{\circ} \mathrm{C}$; or in the presence of $5 \% \mathrm{NaCl}$ at $37^{\circ} \mathrm{C}$. S. typhimurium wild-type C5; $\mathbf{\square}$, S. typhimurium LT1100 (clpP); $\mathbf{\Delta}$, S. typhimurium LT1104 (clpP rpoS); $\triangle$, S. typhimurium LT1108 (rpoS). The data shown are from one of at least three experiments that gave similar results.

comparing growth of an rpoS mutant (LT1108) with the growth of a $c l p P$ rpoS double mutant (LT1104) under the same conditions as the clpP mutant (Fig. 1). We found that while both strains grew like wild-type cells at $37^{\circ} \mathrm{C}$, an increase in temperature or a downshift in $\mathrm{pH}$ resulted in impaired growth of the double mutant as compared to the single mutant or the wild-type. In the presence of a high concentration of salt both of the rpoS mutants were unable to grow, as has been observed previously in E. coli (Hengge-Aronis, 2000). Since the growth of the clpP rpoS mutant was less affected than the $c l p P$ single mutant we conclude that while part of the effect of the clpP mutation is dependent on RpoS, ClpP also promotes growth in stress-exposed cells through an RpoS-independent mechanism. By two-dimensional protein gel analysis we observed that expression of at least 11 proteins was affected by the absence of clpP in- dependently of RpoS, suggesting that these proteins could be related to the observed phenotype (data not shown).

Recently it was shown that the accumulation of another sigma factor, $\sigma^{28}$, encoded by $f l i A$, is also affected by a clpP mutation in S. typhimurium leading to increased levels of FliA and a hyper-flagellate phenotype (Tomoyasu et al., 2002). When we transduced the fliA mutation into C5 and LT1100 and compared growth of the resulting strains under stress we found that fliA did not alter the growth characteristics of the wild-type or the mutant strain, demonstrating that the accumulation of FliA does not account for the observed stress sensitivity of the clpP mutant (data not shown).

During the course of these experiments we observed that LT1100 has a normal colony size. In a recent study, a S. typhimurium clpP mutant displayed a small-colony morphology (Webb et al., 1999), suggesting that LT1100 could carry a secondary mutation. We verified this notion by transducing the transposon-disrupted $c l p P$ allele, $c l p P:: \operatorname{Tn} 10 \mathrm{dTc}$ (Webb et al., 1999) into C5, and found that the resulting C5 clpP mutant had a smallcolony morphology (data not shown). Interestingly, large-colony revertants arose with high frequency, thus showing that the mutant is unsuitable for growth experiments. When we introduced the $c l p P:: \operatorname{Tn} 10 \mathrm{dTc}$ allele into LT1102, which carries the wild-type $c l p P$ allele in the clpP deletion mutant background, the resulting strain, LT1103 (clpP::Tn10dTc), had retained the large-colony morphology, demonstrating that the secondary mutation is unlinked to $c l p P$ (data not shown). However, as growth of LT1102 was identical to growth of C5 and, in addition, LT1103 (clpP::Tn10dTc) behaved like LT1100 $(c l p P)$ under the various stress conditions tested (Fig. 1 and data not shown), our results show that the impaired growth observed for LT1100 is not a consequence of the secondary mutation but rather it is caused by the lack of ClpP.

\section{The absence of ClpP in E. coli also affects growth during stress}

In E. coli the Clp protease degrades intrinsically unfolded protein substrates such as the CRAG protein (Kandror et al., 1999) and a non-secreted alkaline phosphatase mutant protein (Huang et al., 2001), indicating that the proteins formed during stress could be degraded by Clp. The results we obtained with $S$. typhimurium therefore prompted us to analyse how an E. coli clpP mutant behaved when exposed to stress using the same experimental conditions as for S. typhimurium. In agreement with a previous finding (Maurizi et al., 1990b), we found that growth of the E. coli clpP mutant was identical to that of the wild-type at $37^{\circ} \mathrm{C}$ (Fig. 2). However, when the mutant was shifted to $5 \% \mathrm{NaCl}$, to $45^{\circ} \mathrm{C}$ or from neutral $\mathrm{pH}$ to $\mathrm{pH} 4 \cdot 5$, we reproducibly obtained results showing that the growth was impaired compared to the wild-type (Fig. 2) although not to the same extent as observed for the 


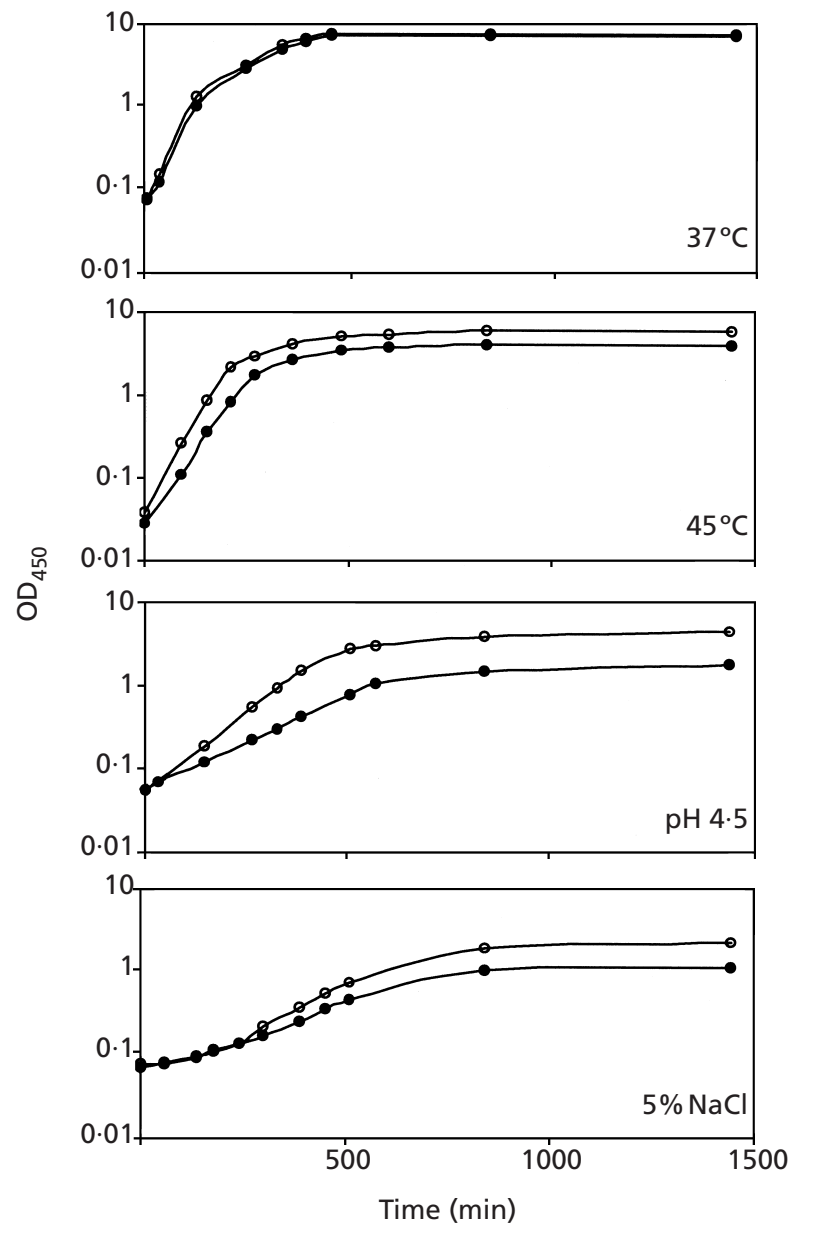

Fig. 2. Growth of the $E$. coli clpP mutant is impaired at low $\mathrm{pH}$. Overnight cultures were diluted into fresh medium and growth was followed under the following conditions: at $37^{\circ} \mathrm{C}$; at $45^{\circ} \mathrm{C}$; at pH 4.5 at $37{ }^{\circ} \mathrm{C}$; or in the presence of $5 \% \mathrm{NaCl}$ at $37^{\circ} \mathrm{C}$. O, E. coli AMS6 (wild-type); O, E. coli AMS6P (clpP). The data shown are from one of at least three experiments that gave similar results.

S. typhimurium clpP mutant. Thus, our results indicate that the $S$. typhimurium clpP mutant is generally more sensitive to stress than the E. coli clpP mutant.

\section{ClpP participates in proteolysis of misfolded protein}

In previous studies it has been shown that $\mathrm{ClpP}$ is important for degradation of misfolded proteins in the Gram-positive bacteria Bacillus subtilis, Listeria monocytogenes and Lactococcus lactis, whereas degradation of such proteins in E. coli is essentially unaffected by a clpP mutation (Frees \& Ingmer, 1999; Gaillot et al., 2000; Kruger et al., 2000; Maurizi et al., 1990b). With the aim of investigating the turnover of misfolded protein in the S. typhimurium clpP mutant, both mutant and wild-type cells were grown in the presence of the tRNA analogue puromycin, which interferes with translation, resulting in the production of misfolded puromycyl-containing peptides. Interestingly, we observed a

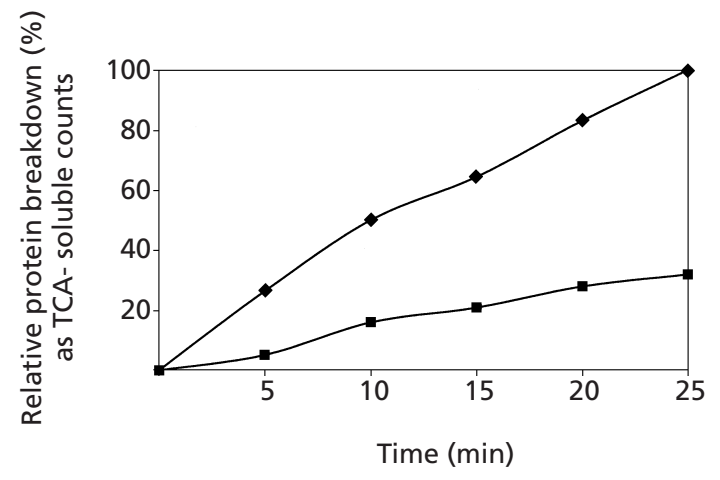

Fig. 3. The $S$. typhimurium $c l p P$ mutant exhibits reduced proteolysis of puromycyl-containing polypeptides. LT1100 and wild-type cells were grown exponentially at $37^{\circ} \mathrm{C}$, and following addition of puromycin cellular proteins were pulselabelled with $\left.{ }^{35} \mathrm{~S}\right]$ methionine. Samples were taken at $5 \mathrm{~min}$ intervals and the relative protein breakdown (\%) was determined as TCA-soluble counts relative to the TCA-soluble counts obtained for wild-type cells $25 \mathrm{~min}$ after the chase. $\bullet$, Wild-type C5; $\mathbf{0}, \mathrm{LT} 1100(\mathrm{clpP})$. The data shown are from one of three experiments, which gave similar results.

decrease in colony size of the $c l p P$ mutant compared to the wild-type, suggesting that the $c l p P$ mutant is more sensitive to puromycin (data not shown). To examine whether a mutation in the $c l p P$ gene affects cellular proteolysis in S. typhimurium, the rate of degradation of puromycyl-containing polypeptides in LT1100 and wildtype cells was determined as described by Raina \& Georgopoulos (1990). The result, presented in Fig. 3, shows that the $c l p P$ mutant degrades these peptides both at a reduced rate and to a lower extent than the wildtype, suggesting that $\mathrm{ClpP}$ is involved in the overall degradation of misfolded proteins in S. typhimurium and that the impaired growth of the mutant could be a result of the accumulation of misfolded proteins. In the literature it has furthermore been reported that the phenotype of an E. coli clpP lon double mutant resembles that of a strain carrying a mutation in lon (Maurizi et al., 1990b), the major ATP-dependent protease responsible for degradation of proteins generated during stress in E. coli (Chung \& Goldberg, 1981; Maurizi et al., 1985). In contrast, the S. typhimurium clpP lon double mutant grows poorly (Wang et al., 1999) although the phenotype of a S. typhimurium lon mutant is similar to that observed in E. coli (Downs et al., 1986). These observations further support the notion that ClpP has a more prominent role in degrading misfolded proteins accumulating during stress in S. typhimurium than in E. coli.

\section{ACKNOWLEDGEMENTS}

We would like to thank G. J. Phillips for supplying the plasmid pTSA29 and A. Matin for the strains AMS6 and AMS6P. Additionally we would like to thank C. G. Buerholt and D. O. Jensen for expert technical assistance. This work was funded by the Danish Ministry of Food, Agriculture and Fisheries. 


\section{REFERENCES}

Chung, C. H. \& Goldberg, A. L. (1981). The product of the lon (capR) gene in Escherichia coli is the ATP-dependent protease, protease La. Proc Natl Acad Sci US A 78, 4931-4935.

De Mot, R., Nagy, I., Walz, J. \& Baumeister, W. (1999). Proteasomes and other self-compartmentalizing proteases in prokaryotes. Trends Microbiol 7, 88-92.

Downs, D., Waxman, L., Goldberg, A. L. \& Roth, J. (1986). Isolation and characterization of lon mutants in Salmonella typhimurium. J Bacteriol 165, 193-197.

Enomoto, M. \& Stocker, B. A. (1974). Transduction by phage P1kc in Salmonella typhimurium. Virology 60, 503-514.

Foster, J. W. \& Spector, M. P. (1995). How Salmonella survive against the odds. Annu Rev Microbiol 49, 145-174.

Frees, D. \& Ingmer, H. (1999). ClpP participates in the degradation of misfolded protein in Lactococcus lactis. Mol Microbiol 31, 79-87.

Gaillot, O., Pellegrini, E., Bregenholt, S., Nair, S. \& Berche, P. (2000). The ClpP serine protease is essential for the intracellular parasitism and virulence of Listeria monocytogenes. Mol Microbiol 35, 1286-1294.

Galan, J. E. (1996). Molecular genetic bases of Salmonella entry into host cells. Mol Microbiol 20, 263-271.

Goff, S. A. \& Goldberg, A. L. (1985). Production of abnormal proteins in E. coli stimulates transcription of lon and other heat shock genes. Cell 41, 587-595.

Goldberg, A. L., Moerschell, R. P., Chung, C. H. \& Maurizi, M. R. (1994). ATP-dependent protease La (lon) from Escherichia coli. Methods Enzymol 244, 350-375.

Gottesman, S. (1996). Proteases and their targets in Escherichia coli. Annu Rev Genet 30, 465-506.

Hanahan, D. (1985). Techniques for transformation of Escherichia coli. In DNA Cloning: a Practical Approach, pp. 109-135. Edited by D. M. Glover. Oxford, UK: IRL Press.

Hengge-Aronis, R. (1996). Back to log phase: sigma $S$ as a global regulator in the osmotic control of gene expression in Escherichia coli. Mol Microbiol 21, 887-893.

Hengge-Aronis, R. (2000). The general stress response in Escherichia coli. In Bacterial Stress Responses, pp. 161-178. Edited by G. Storz \& R. Hengge-Aronis. Washington, DC: American Society for Microbiology.

Hensel, M., Shea, J. E., Gleeson, C., Jones, M. D., Dalton, E. \& Holden, D. W. (1995). Simultaneous identification of bacterial virulence genes by negative selection. Science 269, 400-403.

Hormaeche, C. E. (1979). Natural resistance to Salmonella typhimurium in different inbred mouse strains. Immunology 37, 311-318.

Huang, H. C., Sherman, M. Y., Kandror, O. \& Goldberg, A. L. (2001). The molecular chaperone DnaJ is required for the degradation of a soluble abnormal protein in Escherichia coli. J Biol Chem 276, 3920-3928.

Ibanez-Ruiz, M., Robbe-Saule, V., Hermant, D., Labrude, S. \& Norel, F. (2000). Identification of $\operatorname{RpoS}\left(\sigma^{\mathrm{S}}\right)$-regulated genes in Salmonella enterica serovar typhimurium. J Bacteriol 182, 57495756.

Kandror, O., Sherman, M. \& Goldberg, A. (1999). Rapid degradation of an abnormal protein in Escherichia coli proceeds through repeated cycles of association with GroEL. J Biol Chem 274, 37743-37749.

Kessel, M., Maurizi, M. R., Kim, B., Kocsis, E., Trus, B. L., Singh,
S. K. \& Steven, A. C. (1995). Homology in structural organization between E. coli ClpAP protease and the eukaryotic $26 \mathrm{~S}$ proteasomes. J Mol Biol 250, 587-594.

Kruger, E., Witt, E., Ohlmeier, S., Hanschke, R. \& Hecker, M. (2000). The $c l p$ proteases of Bacillus subtilis are directly involved in degradation of misfolded proteins. J Bacteriol 182, 3259-3265.

Lange, R. \& Hengge-Aronis, R. (1994). The cellular concentration of the sigma $S$ subunit of RNA polymerase in Escherichia coli is controlled at the levels of transcription, translation, and protein stability. Genes Dev 8, 1600-1612.

Laskowska, E., Kuczynska-Wisnik, D., Skorko-Glonek, J. \& Taylor, A. (1996). Degradation by proteases Lon, Clp and HtrA, of Escherichia coli proteins aggregated in vivo by heat shock; HtrA protease action in vivo and in vitro. Mol Microbiol 22, 555-571.

Lee, I. S., Lin, J., Hall, H. K., Bearson, B. \& Foster, J. W. (1995). The stationary-phase sigma factor sigma $\mathrm{S}(\mathrm{RpoS})$ is required for a sustained acid tolerance response in virulent Salmonella typhimurium. Mol Microbiol 17, 155-167.

Loewen, P. C. \& Hengge-Aronis, R. (1994). The role of the sigma factor sigma $\mathrm{S}(\mathrm{KatF})$ in bacterial global regulation. Annu Rev Microbiol 48, 53-80.

Maloy, S. R., Stewart V. J. \& Taylor R. K. (1996). Genetic Analysis of Pathogenic Bacteria. Cold Spring Harbor, NY: Cold Spring Harbor Laboratory.

Maurizi, M. R., Trisler, P. \& Gottesman, S. (1985). Insertional mutagenesis of the lon gene in Escherichia coli: lon is dispensable. J Bacteriol 164, 1124-1135.

Maurizi, M. R., Clark, W. P., Kim, S. H. \& Gottesman, S. (1990a). $\mathrm{ClpP}$ represents a unique family of serine proteases. J Biol Chem 265, 12546-12552.

Maurizi, M. R., Clark, W. P., Katayama, Y., Rudikoff, S., Pumphrey, J., Bowers, B. \& Gottesman, S. (1990b). Sequence and structure of ClpP, the proteolytic component of the ATPdependent Clp protease of Escherichia coli. J Biol Chem 265, 12536-12545

Mhammedi-Alaoui, A., Pato, M., Gama, M. J. \& Toussaint, A. (1994). A new component of bacteriophage $\mathrm{Mu}$ replicative transposition machinery: the Escherichia coli ClpX protein. Mol Microbiol 11, 1109-1116.

Miller, C. G. (1996). Protein degradation and proteolytic modification. In Esherichia coli and Salmonella: Cellular and Molecular Biology, pp. 938-954. Edited by F. C. Neidhardt and others. Washington, DC: American Society for Microbiology.

Miller, J. H. (1992). A Short Course in Bacterial Genetics. Cold Spring Harbor, NY: Cold Spring Harbor Laboratory.

Msadek, T., Dartois, V., Kunst, F., Herbaud, M. L., Denizot, F. \& Rapoport, G. (1998). ClpP of Bacillus subtilis is required for competence development, motility, degradative enzyme synthesis, growth at high temperature and sporulation. Mol Microbiol 27, 899-914.

O'Callaghan, D. \& Charbit, A. (1990). High efficiency transformation of Salmonella typhimurium and Salmonella typhi by electroporation. Mol Gen Genet 223, 156-158.

O’Neal, C. R., Gabriel, W. M., Turk, A. K., Libby, S. J., Fang, F. C. \& Spector, M. P. (1994). RpoS is necessary for both the positive and negative regulation of starvation survival genes during phosphate, carbon, and nitrogen starvation in Salmonella typhimurium. J Bacteriol 176, 4610-4616.

Phillips, G. J. (1999). New cloning vectors with temperaturesensitive replication. Plasmid 41, 78-81.

Porankiewicz, J., Wang, J. \& Clarke, A. K. (1999). New insights 
into the ATP-dependent Clp protease: Escherichia coli and beyond. Mol Microbiol 32, 449-458.

Raina, S. \& Georgopoulos, C. (1990). A new Escherichia coli heat shock gene, $h t r C$, whose product is essential for viability only at high temperatures. J Bacteriol 172, 3417-3426.

Sambrook, J., Fritsch, E. F. \& Maniatis, T. (1989). Molecular Cloning: a Laboratory Manual, 2nd edn. Cold Spring Harbor, NY : Cold Spring Harbor Laboratory.

Schultz, J. E., Latter, G. I. \& Matin, A. (1988). Differential regulation by cyclic AMP of starvation protein synthesis in Escherichia coli. J Bacteriol 170, 3903-3909.

Schweder, T., Lee, K. H., Lomovskaya, O. \& Matin, A. (1996). Regulation of Escherichia coli starvation sigma factor $\left(\sigma^{\mathrm{s}}\right)$ by ClpXP protease. J Bacteriol 178, 470-476.

Spector, M. P., Aliabadi, Z., Gonzalez, T. \& Foster, J. W. (1986). Global control in Salmonella typhimurium: two-dimensional electrophoretic analysis of starvation-, anaerobiosis-, and heat shock-inducible proteins. J Bacteriol 168, 420-424.

Tomoyasu, T., Ohkishi, T., Ukyo, Y. \& 7 other authors (2002). The ClpXP ATP-dependent protease regulates flagellum synthesis in Salmonella enterica serovar Typhimurium. J Bacteriol 184, 645-653.

Wang, J., Hartling, J. A. \& Flanagan, J. M. (1997). The structure of ClpP at $2 \cdot 3 \AA$ resolution suggests a model for ATP-dependent proteolysis. Cell 91, 447-456.

Wang, L., Elliott, M. \& Elliott, T. (1999). Conditional stability of the HemA protein (glutamyl-tRNA reductase) regulates heme biosynthesis in Salmonella typhimurium. J Bacteriol 181, 12111219.
Wawrzynow, A., Wojtkowiak, D., Marszalek, J., Banecki, B., Jonsen, M., Graves, B., Georgopoulos, C. \& Zylicz, M. (1995). The ClpX heat-shock protein of Escherichia coli, the ATP-dependent substrate specificity component of the $\mathrm{ClpP}-\mathrm{ClpX}$ protease, is a novel molecular chaperone. EMBO J 14, 1867-1877.

Wawrzynow, A., Banecki, B. \& Zylicz, M. (1996). The Clp ATPases define a novel class of molecular chaperones. Mol Microbiol 21, 895-899.

Webb, C., Moreno, M., Wilmes-Riesenberg, M., Curtiss, R., III \& Foster, J. W. (1999). Effects of DksA and ClpP protease on sigma $S$ production and virulence in Salmonella typhimurium. Mol Microbiol 34, 112-123.

Wickner, S., Gottesman, S., Skowyra, D., Hoskins, J., McKenney, K. \& Maurizi, M. R. (1994). A molecular chaperone, ClpA, functions like DnaK and DnaJ. Proc Natl Acad Sci USA 91, 12218-12222.

Yamamoto, T., Sashinami, H., Takaya, A., Tomoyasu, T., Matsui, H., Kikuchi, Y., Hanawa, T., Kamiya, S. \& Nakane, A. (2001). Disruption of the genes for ClpXP protease in Salmonella enterica serovar Typhimurium results in persistent infection in mice, and development of persistence requires endogenous gamma interferon and tumor necrosis factor alpha. Infect Immun 69, 3164-3174.

Zgurskaya, H. I., Keyhan, M. \& Matin, A. (1997). The sigma S level in starving Escherichia coli cells increases solely as a result of its increased stability, despite decreased synthesis. Mol Microbiol 24, 643-651.

Received 31 December 2001; revised 23 May 2002; accepted 12 June 2002. 